\title{
The current profile of persistent cloaca and cloacal exstrophy in Japan: the results of a nationwide survey in 2014 and a review of the literature
}

\author{
Masayuki Kubota ${ }^{1}$
}

Accepted: 15 December 2016 / Published online: 5 January 2017

(C) The Author(s) 2017. This article is published with open access at Springerlink.com

\begin{abstract}
Purpose The current profile of persistent cloaca (PC) and cloacal exstrophy (CE) in Japan was first examined in 2014. Materials and methods Information was obtained by sending a questionnaire to 244 university hospitals and children's hospitals.

Results Responses from 113 institutions reported 466 PC cases and $229 \mathrm{CE}$ cases. The incidences of PC and CE from 1980 to 2012 were 0.97 and 0.49 per 100,000 live births, respectively. In the previous 5 years, antenatal abnormalities were found in $57.6 \%$ of PC and $72.7 \%$ of CE patients. Myelomeningocele was observed in $45.6 \%$ of CE patients. As a result of various surgical treatments used in the neonatal and infantile periods, the respective rates of bladder dysfunction, clean intermittent catheterization, and permanent enterostomy were $32.6,22.5$, and $7.3 \%$ in PC patients and $60.7,28.4$, and $73.8 \%$ in CE patients. Menstrual outflow obstruction was found in $22.5 \%$ of PC and $48.9 \%$ of CE patients with menstruation.

Conclusion The clinical outcomes of PC and CE remain unsatisfactory. Therefore, the establishment of treatment guidelines might be a useful objective for improving the current status of PC and CE.
\end{abstract}

Keywords Persistent cloaca $\cdot$ Cloacal exstrophy $\cdot$ A nationwide survey $\cdot$ Menstrual outflow obstruction

\footnotetext{
Masayuki Kubota

kubotama@med.niigata-u.ac.jp

1 Department of Pediatric Surgery, Niigata University Graduate School of Medical and Dental Sciences, 1-757 Asahimachi-Dori, Chuo-ku, Niigata 951-8510, Japan
}

\section{Introduction}

Persistent cloaca (PC) and cloacal exstrophy (CE) are extremely rare congenital anomalies of the anorectum and urogenital tract. PC occurs exclusively in female patients, where the rectum, vagina and urethra converge into a common channel, resulting in a single perineal opening. In contrast, CE is the most severe form of cloaca-related anomaly and it occurs in both sexes; it is characterized by a failure of lower abdominal wall closure, resulting in exstrophy of the intestines and urinary and genital organs. These two diseases are usually associated with multiple anomalies of other organs, which also affect the treatment outcome considerably. Carey et al. [1] described a combination of defects, consisting of omphalocele, exstrophy of the cloaca, imperforate anus, and spinal defects as "OEIS complex".

Because the functional outcomes of surgical treatment of the reproductive system in infancy will become obvious in puberty, these patients need meticulous care from childhood to adulthood. To perform suitable life-long care in these patients, treatment guidelines must be established. However, the precise details of these issues are largely unclear. Furthermore, basic information regarding PC and $\mathrm{CE}$ in the perinatal period, such as the incidence, rate of antenatal diagnosis, and mode of delivery, are also unavailable, due to the lack of a nationwide survey of these two diseases.

We therefore conducted a nationwide survey of PC and CE in 2014 to determine the current status of these diseases in Japan before establishing treatment guidelines. To our knowledge, this survey is the first nationwide survey of PC and CE, performed simultaneously. The results of our survey are introduced here with a review of the literature. 


\section{Patients and methods}

This research project of general-068 entitled, "An establishment of treatment guidelines for smooth transitional care of persistent cloaca, cloacal exstrophy and Mayer-RokitanskyKuster-Hauser syndrome," was supported by the Health and Labour Sciences Research Grants for Research on Rare and Intractable Diseases from 2014 to 2016 in Japan. The results of a nationwide survey concerning PC and CE are presented in this manuscript. Table 1 lists the research members who participated in the present survey. The Ethics Committee of Niigata University School of Medicine approved the study protocol of the research project and nationwide survey (approved number of 1888).

Information was obtained by sending a questionnaire to 244 university hospitals and children's hospitals in Japan to investigate the etiologic events and clinical outcomes in patients with PC and CE. Responses were obtained from 113 institutions (46.3\%) regarding 466 cases of PC and 229 cases of CE, which were the total of cases treated in the past. Roughly 300 events and parameters were examined in the following order: perinatal events, associated anomalies, surgical treatments shortly after birth, radical operations, renal and bladder function, reproductive organ function, and school and social life. Since national birth statistics in Japan were available up to 2012, the incidence of diseases for every 100,000 live births was calculated for patients born between 1980 and 2012.

\section{Statistical analyses}

The statistical analyses were performed using a commercially available software program (Prism 6 for Mac OS $\mathrm{X}$ version $6.0 \mathrm{~b}$; La Jolla, California, USA). The results are expressed as the median. Statistically significant differences between the groups were estimated using independent Student's $t$ test or the Mann-Whitney $U$ test. Differences were considered to be significant for values of $p<0.05$.

Table 1 Lists of research members participating in the nationwide survey

\begin{tabular}{|c|c|}
\hline Name & Institute, department \\
\hline Yutaka OSUGA & Graduate School of Medicine, the University of Tokyo, Department of Obstetrics and Gynecology \\
\hline Kiyoko KATO & Graduate School of Medial Sciences Kyushu University, Department of Gynecology and Obstetrics \\
\hline Kenji ISHIKURA & National Center for Child Health and Development, Division of Nephrology and Rheumatology \\
\hline Kazunari KANEKO & Kansai Medical University, Department of Pediatrics \\
\hline Kohei AKAZAWA & Niigata University Graduate School of Medical and Dental Sciences, Department of Medical Informatics \\
\hline Yoshiaki KINOSHITA & Graduate School of Medical Sciences Kyushu University, Department of Pediatric Surgery \\
\hline Takeo YONEKURA & Nara Hospital, Kindai University Faculty of Medicine, Department of Pediatric Surgery \\
\hline Yuko TAZUKE & Osaka University Graduate School of Medicine, Department of Pediatric Surgery \\
\hline Satoshi IEIRI & Kagoshima University, Research Field in Medicine and Health Sciences, Department of Pediatric Surgery \\
\hline Akihiro FUJINO & National Center for Child Health and Development, Devision of Pediatric Surgery \\
\hline Shigeru UENO & Tokai University School of Medicine, Department of Pediatric Surgery \\
\hline Yutaro HAYASHI & Nagoya City University Graduate School of Medical Sciences, Department of Nephro-urology \\
\hline Kaoru YOSHINO & Aichi Children's Health and Medical Center, Department of Urology \\
\hline Toshihiro YANAI & Ibaraki Children's Hospital, Department of Pediatric Surgery and Pediatric Urology \\
\hline Jun IWAI & Chiba Children's Hospital, Department of Pediatric Surgery \\
\hline Takanori YAMAGUCHI & Fukuoka Children's Hospital, Department of Urology \\
\hline Shintaro AMAE & $\begin{array}{l}\text { Ekoh-Ryoikuen Hospital-homes for persons with severe motor and intellectual disabilities (SMID), } \\
\text { Department of Surgery }\end{array}$ \\
\hline Yuichiro YAMAZAKI & Kanagawa Children's Medical Center, Department of Urology \\
\hline Yoshifumi SUGITA & Kobe Children's Hospital, Department of Urology \\
\hline Miyuki KOHNO & Kanazawa Medical University, Department of Pediatric Surgery \\
\hline Yutaka KANAMORI & National Center for Child Health and Development, Devision of Pediatric Surgery \\
\hline Yuko BITOH & Kobe University Hospital, Department of Pediatric Surgery \\
\hline Masato SHINKAI & Kanagawa Children's Medical Center, Department of Surgery \\
\hline Yasuharu OHNO & Oita University Faculty of Medicine, Department of Gastroenterological and Pediatric Surgery \\
\hline Yuhki ARAI & Niigata University Graduate School of Medical and Dental Sciences, Department of Pediatric Surgery \\
\hline
\end{tabular}




\section{Embryology}

PC and CE are considered to be a spectrum of disease that affects the formation of the cloaca. CE patients show the most severe form of cloacal anomaly, associated with omphalocele, pubic bone dehiscence, and frequently with myelomeningocele. Briefly, the body wall is constructed in the fourth gestational week. In the same period, the neural tube is also created. Major events that cause the failure of the anterior abdominal wall closure can therefore also disturb the neural tube formation, which might be a reason for the strong association with myelomenigocele in $\mathrm{CE}$ patients [2]. The division of the cloaca occurs in the next developmental stage. The urorectal septum differentiates the cloaca into the urogenital tract and the anorectal tract $[3,4]$. However, a recent anatomical study using animal models of anorectal malformation found that the normally developing cloaca differed starkly from any form of anorectal malformation, including persistent cloaca, where the cloacal membrane was too short to function as the dorsal cloaca [5]. Therefore, further studies are necessary to clarify the precise developmental aspect of PC and CE.

\section{Results}

\section{Perinatal events}

Prevalence of $P C$ and $C E$

The oldest cases of PC and CE in this nationwide survey were found in 1961 and 1969, respectively (Fig. 1). In the past 25 years, from 1990 to 2014 , the average annual occurrence was 14.8 and 7.1 cases for PC and $\mathrm{CE}$, respectively. The overall prevalence of patients per 100,000 live births from 1980 to 2012 was 0.97 and 0.49 for PC and CE, respectively. The incidence of PC has

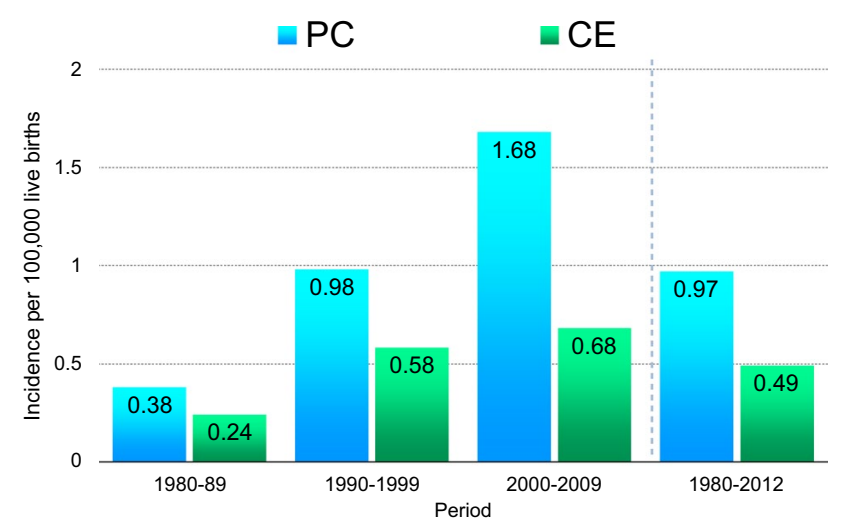

Fig. 2 Prevalence of PC and CE patients per 100,000 live births for 1980-1989, 1990-1999, 2000-2009, and 1980-2012 in Japan. PC persistent cloaca, $C E$ cloacal exstrophy
Fig. 1 Annual occurrence of $P C$ and CE in Japan. PC persistent cloaca, $C E$ cloacal exstrophy
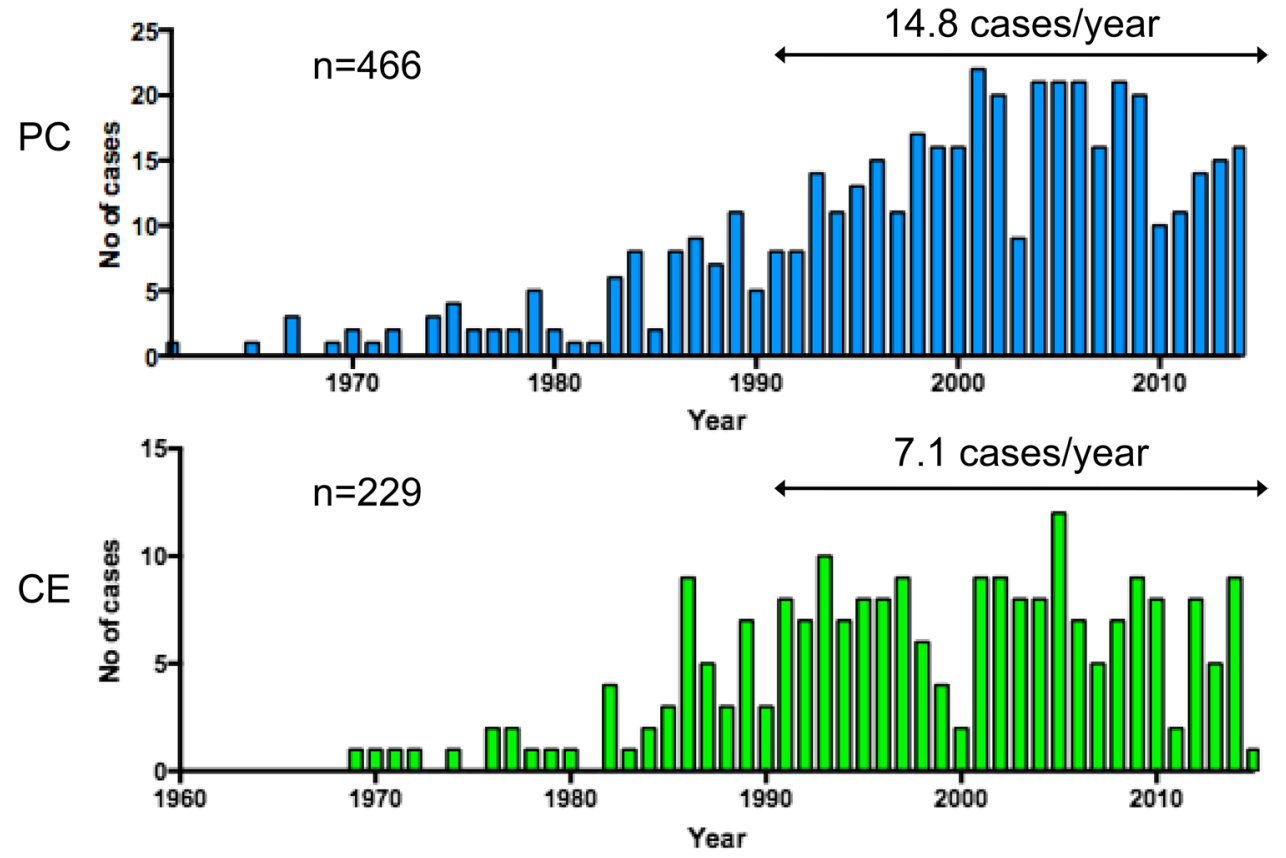


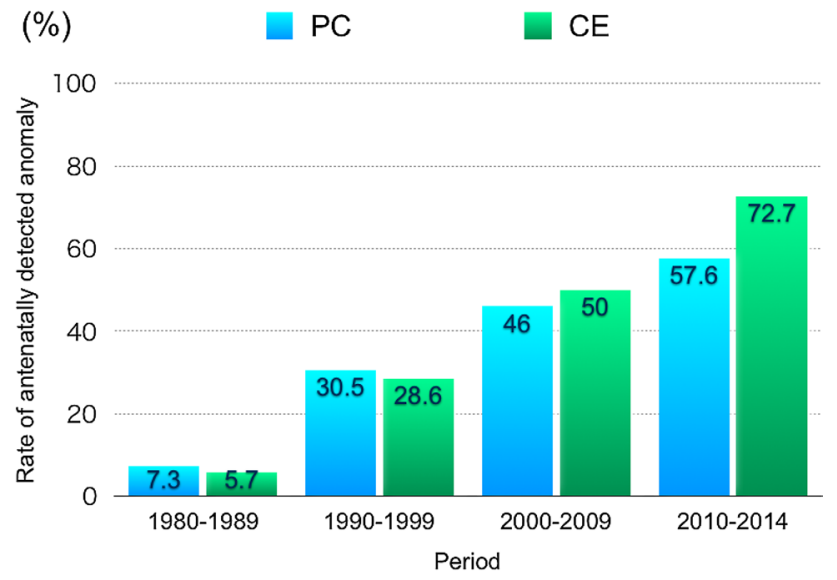

Fig. 3 Trends in the rate of antenatal detection of fetal anomalies in $\mathrm{PC}$ and CE patients. $P C$ persistent cloaca, $C E$ cloacal exstrophy

been increasing over the past 30 years while that of $\mathrm{CE}$ has remained relatively stable (Fig. 2).

Prior to 1960 , nearly all CE patients died due to intestinal obstruction and urosepsis [6]. The prevalence of PC per 100,000 live births was reported to be 2.0 in one study [7], while the prevalence of CE per 100,000 live births in several studies was 0.4 [8], 0.5 [9], or 0.6 [10], roughly corresponding to 1 in every 170,000 and 250,000 live births. An International Clearinghouse for Birth Defects Surveillance and Research study found that the prevalence of CE per 100,000 births was 0.76 , which was an average of 18 surveillance programs, with a range of $0.6-2.25$ [11]. These findings suggest that the prevalence of PC and CE in Japan might be similar to those of Western countries.

\section{Antenatal detection of fetal anomalies}

The incidence of antenatal detection of fetal anomalies in PC and CE patients has been steadily increasing in both PC and CE patients in Japan (Fig. 3). In PC patients, pelvic cyst, hydronephrosis, oligohydramnios, and ascites were frequently found by ultrasonography. The signs for PC patients are mainly those of abnormalities inside the body, while for CE patients, the signs are mainly visible on the body surface, such as omphalocele, myelomenigocele, and abnormal genitalia, all of which are detected by ultrasonography.

Even though the antenatally detectable abnormalities in PC patients are mainly those of associated anomalies, hydronephrosis and bilobed or multilocular pelvic cyst in female fetuses have been suggested to be signs of PC itself $[12,13]$. The rate of diagnosis of PC has been reported to be as low as 6\%, even though the rate of detection of fetal anomalies in PC patients was 54\% [14]. An accurate antenatal diagnosis of CE was achieved with fetal magnetic resonance imaging (MRI), which revealed a protuberant abdominopelvic contour, absence of a normal bladder, and a meconium-filled rectum and colon [15]. Serial MRI studies have also been suggested to be useful in the accurate diagnosis and understanding of the associated pathologies in the affected fetus [16].

\section{Mode of delivery}

In our survey, the rates of vaginal delivery were 54.8 and $51.7 \%$ in mothers of PC and CE fetuses, respectively. The rates of cesarean section in mothers of PC and CE fetuses were also similar, with rate of 37.7 and $42.0 \%$, respectively. However, the main reason for a cesarean section was different between mothers of $\mathrm{PC}$ and $\mathrm{CE}$ fetuses. In mothers of PC fetuses, fetal distress was the most frequent reason for cesarean sections (31.7\%), followed by fetal diseases (24.4\%) and fetopelvic disproportion $(23.7 \%)$. On the contrary, in mothers of CE fetuses, fetal disease $(23.7 \%)$, myelomeningocele $(15.8 \%)$, threatened premature delivery (15.8\%), and early rupture of membranes $(15.8 \%)$ were the main reasons for cesarean section.

PC is not considered an indication for cesarean section. However, in severe forms of abdominal wall defect, such as cloacal exstrophy, multi-disciplinary counseling and management are recommended [17]. In CE, there are complex management issues, such as gender assignment, a treatment plan and assessment of disability, and optimal management that require collaboration among specialists.

The median number of gestational weeks at delivery of the patients was significantly longer in PC patients than in CE patients (38.0 vs. 36.0 weeks, $p<0.0001)$. Correspondingly, $\mathrm{PC}$ babies were significantly heavier than $\mathrm{CE}$ babies $(2,732$ vs. $2441 \mathrm{~g}, p<0001)$.

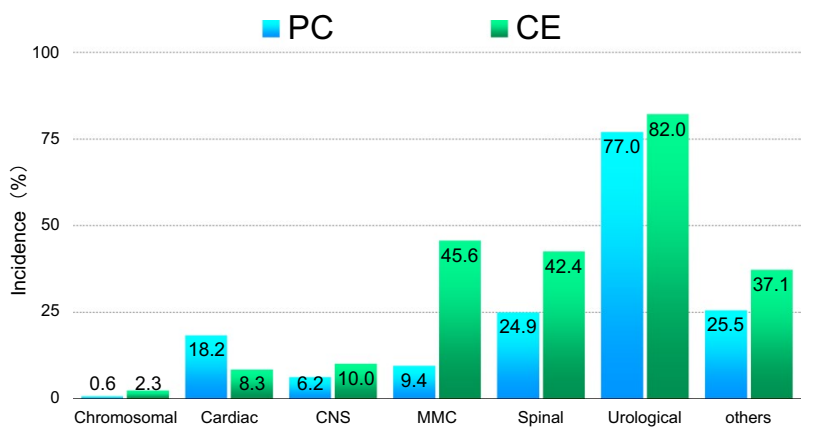

Fig. 4 Associated anomalies in PC and CE patients. $P C$ persistent cloaca, $C E$ cloacal exstrophy, Chromosomal chromosomal anomaly, Cardiac cardiac anomaly, CNS anomaly of central nervous system, $M M C$ myelomeningocele, Spinal spinal anomaly, Urological anomaly of urinary tract 
Table 2 Urinary tract anomalies in PC and CE patients

\begin{tabular}{lcc}
\hline & PC cases $(\%)$ & CE cases $(\%)$ \\
\hline Hydronephrosis & $136(29.1)$ & $56(24.5)$ \\
Hypoplasia or dysplasia & $72(15.5)$ & $19(8.3)$ \\
Renal agenesis & $44(9.4)$ & $19(8.3)$ \\
Megaureter & $30(6.4)$ & $15(6.6)$ \\
Duplex system & $15(3.2)$ & $8(3.5)$ \\
Multicystic DK & $15(3.2)$ & $1(0.4)$ \\
Horseshoe kidney & $12(2.6)$ & $2(0.9)$ \\
Ureterocele & $3(0.6)$ & $2(0.9)$ \\
\hline
\end{tabular}

$P C$ persistent cloaca, $C E$ cloacal exstrophy, $D K$ dysplastic kidney

\section{Associated anomalies}

The associated anomalies are summarized in Fig. 4. Chromosomal anomalies were rare in both PC and CE patients, but cardiac anomaly was much more frequently observed in PC patients than in CE patients. Of note, myelomeningocele and other spinal anomalies were found in 45.6 and $42.4 \%$ of CE patients, respectively. As a result, about $90 \%$ of CE patients had some type of anomaly of the spinal tract at birth. The association of spinal anomalies might be an important factor influencing the diminished bowel and bladder function in CE patients. Urinary tract anomalies were equally observed in both groups of patients at a frequency of roughly $80 \%$. The urinary tract anomalies are shown in Table 2. Hydronephrosis was the most frequently found in both PC and CE patients, followed by a variety of diseases. The prevalence of renal hypoplasia or dysplasia, multicystic dysplastic kidney, and horseshoe kidney was higher in PC patients than in CE patients.

Regarding anomalies of the internal genitalia in PC patients, a double uterus (50.0\%) or double vagina (35.2\%) was frequently observed. Retention of fluid, such as hydrocolpos (23.6\%), hydrometra (23.6\%), and hydrosalpinx (5.4\%) was the next most frequent after duplex anomalies. In total, $90 \%$ of patients had some type of anomaly of the internal genitalia. In CE patients, the presence of a uterus, vagina, fallopian tube, and testes was confirmed in 25.0, $12.7,20.0$ and $26.2 \%$ of patients, respectively.

In a single-center study of $17 \mathrm{CE}$ patients [18], abnormalities of the vertebral column and/or spinal cord were found in 16 patients $(94.1 \%)$. Four patients had lipomyelomeningocele, and nine had lipomeningocele. Another single-center analysis of $25 \mathrm{CE}$ patients [19] found vertebral anomalies in all 25 patients. In addition, all 19 patients who underwent MRI showed myelodysplasia. Of these 19 patients, 15 had myelocystocele, 2 had lipomeningocele, and 2 had meningocele. The findings from these two studies are quite in accordance with those of the present survey that $90 \%$ of the patients were associated with myelomeningocele and/or spinal anomalies. Regarding the association of urological anomalies in PC patients, 32 (68.0\%) out of 47 patients were reported to have urological defects [20].

Regarding the reproductive system, vaginal agenesis, double vagina, and single vagina were reported in 12 (11.4\%), 42 (40.0\%), and 52 (49.5\%) of 105 PC patients in single-center study, respectively [21]. Pena [20] described a wide spectrum of the anatomic variation in PC patients, where different degrees of vaginal and uterine separation was found in half of 50 patients. In genetically female CE patients, two widely separated vaginas were confirmed when the patients underwent vaginal reconstruction at puberty $[6,22]$. The ovaries and tubes are generally normal in female PC patients [23]. In genetically male CE patients, the phallus is also divided and separated. Husman et al. [24] reported diminutive or absent penis in $30 \%$ of patients. Even though cryptorchidism was frequent in genetically male CE patients, the testicular histology was reported to be preserved [25].

\section{Gender assignment}

In this study, gender assignment in half of the CE patients was determined based on the results of a sex chromosome analysis. A total of $91 \mathrm{CE}$ patients were thereby determined to be genetically male, and 116 were determined to be genetically female, resulting in a male-to-female ratio of 0.78 . Of these 91 genetically male CE patients, 21 were raised as girls.

Other studies have reported a genetically male-to-genetically female ratio of 0.86 [19] and 1.27 [26]. Regarding the gender identity outcome, female-raised 46XY CE patients are reportedly at risk of later patient-initiated gender reassignment to male after female assignment in infancy or early childhood, an outcome which has also been observed in patients with penile agenesis or penile ablation [27]. In our series, four 46XY CE cases assigned as female changed their sex to male in adolescence.

\section{Surgical treatments shortly after birth}

Stoma was created in most PC patients $(95.5 \%)$ and CE patients (91.3\%). In $104 \mathrm{CE}$ patients (45.4\%), a stoma was placed in the hindgut, while the ileum was used in 51 cases $(22.3 \%)$. In contrast, the transverse or sigmoid colon was mainly used in $60.9 \%$ and $19.7 \%$ of PC patients, respectively. Vesical operation was performed in $25.1 \%$ of PC patients, while this rate was $80.8 \%$ in CE patients. In PC patients, vesicostomy was performed in $86.5 \%$ of the patients who underwent vesical operation, while primary closure of the bladder was performed in $69.1 \%$ of CE patients who underwent vesical operation. In CE patients, a 
Table 3 Anoplasty without vaginoplasty in PC and CE patients

\begin{tabular}{lll}
\hline Method of operation & PC 153 cases & CE 18 cases \\
\hline Abdomino-perineal pull-through & 54 & 8 \\
PSARP & 41 & 2 \\
Sacroperineal pull-through & 14 & 2 \\
Abdomino-sacroperineal pull-through & 11 & \\
Laparoscopic operation & 8 & \\
Perineal approach & 3 & \\
\hline
\end{tabular}

$P C$ persistent cloaca, $C E$ cloacal exstrophy, PSARP posterior sagittal anorectoplasty

variety of other operations were performed. Pubic and pelvic bone plasty and abdominal wall closure were performed in 64.2 and $80.8 \%$ of CE patients, respectively.

\section{Radical operations}

\section{Anoplasty and vaginoplasty}

Table 3 shows the major operative procedures for anoplasty without vaginoplasty and number of patients who underwent the corresponding operations. Anoplasty without vaginoplasty was performed in $32.8 \%$ of PC patients and $7.9 \%$ of CE patients, and abdomino-perineal pull-through operation was the most frequent method in both groups of patients, followed by posterior sagittal anorectoplasty (PSARP) and sacroperineal operation.

Table 4 describes the major operative procedures for anoplasty and vaginoplasty performed simultaneously, which was exclusively found in PC patients. Cases in which the procedures for the vaginoplasty and anoplasty were the same or different are shown separately. Posterior sagittal anorectourethrovaginoplasty (PSARUVP) was the method most frequently used for anovaginoplasty, while total urogenital mobilization and intestinal interposition was the method most frequently used for vaginoplasty. In contrast, in CE patients, only 24 patients
(10.5\%) underwent vaginoplasty. The main type of operation was reconstruction using the ileum, bladder, colon, or cecum. The rate of patients who decided to have permanent stoma was 10 times higher in CE patients than in PC patients (73.8 vs. $7.3 \%$ ). This difference might be due to the higher incidence of myelomeningocele in $\mathrm{CE}$ patients than in PC patients.

\section{Operation on the urinary tract and outcomes}

Bladder augmentation was performed in 7 PC patients (1.5\%) and 62 CE patients (27.0\%), respectively. Route creation for clean intermittent catheterization (CIC) was done in $70 \mathrm{PC}$ patients $(15.0 \%)$ and $16 \mathrm{CE}$ patients (7.0\%). The rate of a radical operation for VUR was similar between PC and CE patients (15.0 vs. 15.3\%). Among CE patients, orchidopexy was performed in 37 patients $(16.1 \%)$ and phalloplasty in $17(7.4 \%)$.

Regarding the renal function, 35 PC patients $(7.5 \%)$ and $26 \mathrm{CE}$ patients (11.4\%) had a creatinine level above $1.0 \mathrm{mg} / \mathrm{ml}$. Even though the renal function was relatively well preserved, bladder dysfunction was observed in 152 PC patients $(32.6 \%)$ and $139 \mathrm{CE}$ patients $(60.7 \%)$. The rate of patients with CIC was similar between the PC (105 cases; 22.5\%) and CE patients (65 cases; 28.4\%). The number of cases starting dialysis or receiving kidney transplantation was $15 \mathrm{PC}$ cases and $3 \mathrm{CE}$ cases.

\section{Reproductive organ function}

Menstruation was observed in 178 PC patients (38.4\%) and $45 \mathrm{CE}$ patients with a karyotype of 46XX (38.8\%). The occurrence of a menstrual disorder, menstruation blood outflow block, volume disorder, and cycle disorder was observed in $35.4,22.5,31.4$, and $42.1 \%$ of the 178 PC patients and in $58.7,48.9,42.2$, and $30.4 \%$ of the 45 CE patients, respectively.
Table 4 Anoplasty with vaginoplasty in PC patients

\begin{tabular}{lrlr}
\hline $\begin{array}{l}\text { Anovaginoplasty in the same operation } \\
\text { method }\end{array}$ & 232 cases & $\begin{array}{l}\text { Vaginoplasty performed by the dif- } \\
\text { ferent method to anoplasty }\end{array}$ & 144 cases \\
\hline PSARUVP & 170 & TUM & 41 \\
Abdomino-perineal pull-through & 6 & Intestinal interposition & 35 \\
TUM & 4 & Anterior skin flap & 24 \\
Perineal anovaginoplasty & 4 & PUM + skin flap & 9 \\
Hendren's operation & 2 & Skin flap & 9 \\
PUM & 1 & Vaginal switch & 5 \\
Sacroperineal pull-through & 1 & PUM & 2 \\
\hline
\end{tabular}

$P C$ persistent cloaca, $P S A R U V P$ posterior sagittal anorectourethrovaginoplasty, $T U M$ total urogenital mobilization, $P U M$ partial urogenital mobilization 


\section{Literature review of radical operations}

Surgical repair of the anus, bladder, and vagina in CE patients is still challenging. The high prevalence of neurological abnormalities might affect the post-operative urinary and bowel continence, thereby limiting the indications of anoplasty. In a study of the neurological function of 21 CE patients [19], 15 (71.4\%) were community ambulators, while 1 (4.8\%) was a nonfunctional ambulator and $6(28.6 \%)$ were nonambulators. Therefore, roughly one third of CE patients have some degree of motor dysfunction of the lower extremities. In our series, half of CE patients were associated with myelomeningocele, which might be related to the low incidence of radical operation in $\mathrm{CE}$ patients. In a large series of $50 \mathrm{CE}$ patients [26], 40 underwent extensive reconstructive surgery. Of these 40 patients, the number who underwent bladder augmentation, pullthrough of the colon, and vaginal reconstruction was 35 (87.5\%), 25 (14.3\%), and 32 patients (80\%), respectively. A total of 31 of these 40 reconstructed cases were dry, and acceptable bowel continence was achieved in 19 of 25 pullthroughs. The hind gut is strongly recommended for the initial colostomy, since future colon pull-through is essential for successful bowel management [28, 29]. Therefore, the use of the colon for urologic and genital reconstruction should be avoided.

In a large series of PC patients consisting of 490 cases [30], the length of the common channel affected the surgical outcomes. Patients with a short common channel (length $<3 \mathrm{~cm}$ ) comprised $56 \%$ of patients and showed a better bowel habit and urinary continence after radical operation than those with longer channels. In these patients, radical operation was performed via the posterior sagittal approach, and total urogenital mobilization without laparotomy. In this study, the method chosen for anoplasty without vaginoplasty was either abdomino-perineal pull-through or PSARP. In addition, while PSARP was the most frequently used method for anovaginoplasty where both operations were performed via the same method, total urogenital mobilization or intestinal interposition was the most frequently used when vaginoplasty was performed via a different method from anoplasty.

\section{Social and school life}

Patients with lovers or spouses comprised 5.8 and $2.2 \%$ of the PC and CE patients, respectively. Coitus before marriage was reported in about 3.0 and $2.6 \%$ of $\mathrm{PC}$ and $\mathrm{CE}$ patients. Seventeen PC patients (3.6\%) and 5 CE patients (2.2\%) were married. Childbearing was noted in four PC patients and none of the CE patients.

The rate of patients who attended a special needs school was higher among CE patients than PC patients (14 CE patients [6.1\%] vs. 9 PC patients [1.9\%]). Bowel and urinary troubles at school were noted in $67(28.1 \%)$ and 59 (25.2\%) PC patients and $28(28.5 \%)$ and $42(42.4 \%)$ CE patients, respectively. While the rate of bowel trouble was similar between the two groups of patients, urinary trouble was much more frequent in CE patients than in PC patients.

Childbirth is sporadically reported among both PC patients [31, 32] and CE patients [33]. One PC case delivered vaginally in the first pregnancy, and then cesarean section was performed for a triplets pregnancy after in vitro fertilization [31, 32]. The risks associated with cesarean section due to multiple previous operations have been well addressed. However, careful consideration of the patient's genital condition and well-organized team counseling might be advisable before childbirth is attempted in PC and CE patients.

The quality of life among PC and CE patients is an important clinical issue, as many patients are now living longer due to the advancements of modern medicine. One study at Johns Hopkins University [34] suggested that a reduction in incontinent stomas, assistance with ambulation, and improved cosmesis might be useful for improving these patients' quality of life. CE patients are reported to have relatively good psychological functioning, and appropriate support for these patients can ensure they have remarkably well-adjusted lives [35].

\section{Conclusions}

A comparative study of PC and CE patients may be useful for clarifying the characteristics of both diseases. In Japan, the prevalence of CE patients was just half of that of PC patients, and the major anomalies differ between these two groups of patients. We also clearly showed that the surgical outcomes of PC and CE patients were still not satisfactory. A majority of patients require continual care from childhood to adulthood, especially in the treatment of urological and gynecological morbidities. Therefore, treatment guidelines for the smooth transitional care of PC and CE patients should be established, a task currently being attempted by our research team.

\section{Compliance with ethical standards}

Conflict of interest No potential COI to disclose.

Open Access This article is distributed under the terms of the Creative Commons Attribution 4.0 International License (http:// creativecommons.org/licenses/by/4.0/), which permits unrestricted use, distribution, and reproduction in any medium, provided you give appropriate credit to the original author(s) and the source, provide a link to the Creative Commons license, and indicate if changes were made. 


\section{References}

1. Carey JC (2001) Exstrophy of the cloaca and the OEIS complex: one and the same. Am J Med Genet 99:270

2. Athavale SA (2012) Deciphering caudal embryonic defects: embryological analysis and reviewing literature data. Rom $\mathbf{J}$ Morphol Embryol 53:1013-1020

3. de Vries PA, Friedland GW (1974) The staged sequential development of the anus and rectum in human embryos and fetuses. $\mathrm{J}$ Pediatr Surg 9:755-769

4. Stephens FD (1988) Embryology of the cloaca and embryogenesis of anorectal malformations. Birth Defects Orig Artic Ser 24:177-209

5. Kluth D (2010) Embryology of anorectal malformations. Semin Pediatr Surg 19:201-208

6. Lund DP, Hendren WH (1993) Cloacal exstrophy: experience with 20 cases. J Pediatr Surg 28:1360-1368 (discussion 1368-1369)

7. Forrester MB, Merz RD (2004) Impact of excluding cases with known chromosomal abnormalities on the prevalence of structural birth defects, Hawaii, 1986-1999. Am J Med Genet A 128a:383-388

8. Evans JA, Darvill KD, Trevenen C, Rockman-Greenberg C (1985) Cloacal exstrophy and related abdominal wall defects in Manitoba: incidence and demographic factors. Clin Genet 27:241-251

9. Martinez-Frias ML, Bermejo E, Rodriguez-Pinilla E, Frias JL (2001) Exstrophy of the cloaca and exstrophy of the bladder: two different expressions of a primary developmental field defect. Am J Med Genet 99:261-269

10. Caton AR, Bloom A, Druschel CM, Kirby RS (2007) Epidemiology of bladder and cloacal exstrophies in New York State, 19831999. Birth Defects Res A Clin Mol Teratol 79:781-787

11. Feldkamp ML, Botto LD, Amar E, Bakker MK et al (2011) Cloacal exstrophy: an epidemiologic study from the International Clearinghouse for Birth Defects Surveillance and Research. Am J Med Genet C Semin Med Genet 157c:333-343

12. Warne S, Chitty LS, Wilcox DT (2002) Prenatal diagnosis of cloacal anomalies. BJU Int 89:78-81

13. Suzumori N, Obayashi S, Hattori Y et al (2009) Prenatal diagnosis of persistent cloaca. Congenit Anom (Kyoto) 49:116-117

14. Livingston JC, Elicevik M, Breech L et al (2012) Persistent cloaca: a 10 -year review of prenatal diagnosis. J Ultrasound Med 31:403-407

15. Calvo-Garcia MA, Kline-Fath BM, Rubio EI et al (2013) Fetal MRI of cloacal exstrophy. Pediatr Radiol 43:593-604

16. Yamano T, Ando K, Ishikura R, Hirota S (2011) Serial fetal magnetic resonance imaging of cloacal exstrophy. Jpn J Radiol 29:656-659

17. Prefumo F, Izzi C (2014) Fetal abdominal wall defects. Best Pract Res Clin Obstet Gynaecol 28:391-402
18. McLaughlin KP, Rink RC, Kalsbeck JE et al (1995) Cloacal exstrophy: the neurological implications. J Urol 154:782-784

19. Weaver KB, Matthews H, Chegini S et al (1997) Vertebral column and spinal cord malformation in children with exstrophy of the cloaca, with emphasis on their functional correlates. Teratology 55:241-248

20. Pena A (1989) The surgical management of persistent cloaca: results in 54 patients treated with a posterior sagittal approach. J Pediatr Surg 24:590-598

21. Hendren WH (1992) Cloacal malformations: experience with 105 cases. J Pediatr Surg 27:890-901

22. Hisamatsu E, Nakagawa Y, Sugita Y (2014) Vaginal reconstruction in female cloacal exstrophy patients. Urology 84:681-684

23. Schober JM, Carmichael PA, Hines M, Ransley PG (2002) The ultimate challenge of cloacal exstrophy. J Urol 167:300-304

24. Husmann DA, McLorie GA, Churchill BM (1989) Phallic reconstruction in cloacal exstrophy. J Urol 142:563-564 (discussion 572)

25. Mathews RI, Perlman E, Marsh DW, Gearhart JP (1999) Gonadal morphology in cloacal exstrophy: implications in gender assignment. BJU Int 84:99-100

26. Lund DP, Hendren WH (2001) Cloacal exstrophy: a 25-year experience with 50 cases. J Pediatr Surg 36:68-75

27. Meyer-Bahlburg HF (2005) Gender identity outcome in femaleraised 46,XY persons with penile agenesis, cloacal exstrophy of the bladder, or penile ablation. Arch Sex Behav 34:423-438

28. Taghizadeh A, Qteishat A, Cuckow PM (2009) Restoring hindgut continuity in cloacal exstrophy: a valuable method of optimising bowel length. Eur J Pediatr Surg 19:141-144

29. Levitt MA, Mak GZ, Falcone RA Jr, Pena A (2008) Cloacal exstrophy-pull-through or permanent stoma? A review of 53 patients. J Pediatr Surg 43:164-168 (discussion 168-170)

30. Levitt MA, Pena A (2010) Cloacal malformations: lessons learned from 490 cases. Semin Pediatr Surg 19:128-138

31. Greenberg JA, Hendren WH (1997) Vaginal delivery after cloacal malformation repair. Obstet Gynecol 90:666-667

32. Greenberg JA, Wu JM, Rein MS, Hendren WH (2003) Triplets after cloacal malformation repair. J Pediatr Adolesc Gynecol $16: 43-44$

33. Gezer A, Guralp O, Yesilbas C, Madazli R (2011) Spontaneous pregnancy and birth with corrected cloacal exstrophy. Acta Obstet Gynecol Scand 90:413-414

34. Mathews R, Jeffs RD, Reiner WG, Docimo SG, Gearhart JP (1998) Cloacal exstrophy-improving the quality of life: the Johns Hopkins experience. J Urol 160:2452-2456

35. Mukherjee B, McCauley E, Hanford RB, Aalsma M, Anderson AM (2007) Psychopathology, psychosocial, gender and cognitive outcomes in patients with cloacal exstrophy. J Urol 178:630-635 (discussion 634-635) 